\title{
Los consumidores como sujetos de tutela: Una mirada desde las normas antimonopólicas, de competencia leal y de protección del consumo
}

\section{Consumers as subjects of tutelage: A look from the antitrust rules, fair competition and consumer protection}

\author{
Felipe Vega Gómez ${ }^{1}$
}

\section{RESUMEN}

Se abordará la discusión en torno a los ámbitos de protección del consumidor en el orden público económico. Específicamente, en el ámbito de la normativa de libre competencia, de protección de derechos de los consumidores y la regulación de la competencia desleal. Para lograr este propósito, diferenciaremos entre protección directa e indirecta, concluyendo que el bienestar del consumidor no es parte de la tutela dispensada por la legislación antimonopólica.

Palabras claves: Consumidores - bien jurídico protegido - libre competencia - competencia desleal.

\section{ABSTRACT}

In this work, we will discuss areas of consumer protection in the public economic order. Specifically, in the field of free competition regulations, protection of consumer rights, and the control of the unfair competition. To achieve this purpose, we will differentiate between direct and indirect protection, concluding that consumer welfare is not part of the guardianship provided by antitrust legislation.

Keywords: Consumers - protected object - antitrust - unfair competition.

Felipe Vega Gómez. Abogado, Pontificia Universidad Católica de Chile. Diplomado en Derecho de la Libre Competencia, Universidad Adolfo Ibáńez y Diplomado en Derechos Fundamentales, Universidad Gabriela Mistral. Doctorando en Derecho, Universidad de los Andes, Chile. Correo: fovega@uc.cl 


\section{Planteamiento de la problemática}

La jurisprudencia de la Corte Suprema tradicionalmente ha identificado el bien jurídico protegido por el derecho a la competencia ${ }^{2}$ como el bienestar del consumidor. Sin embargo, este fin de las normas del Decreto Ley No 211 es cuestionado en la actualidad por las autoridades de libre competencia, identificando otros bienes jurídicos como la innovación, el proceso competitivo mismo e, incluso, la igualdad social, como el objeto de la protección por las normas de defensa de la competencia. Por otra parte, otras leyes que regulan la conducta en el mercado también realizan referencia a los consumidores como grupos sujetos de su tutela, como es el caso de la ley que regula competencia desleal, que también entiende que la competencia leal entre competidores beneficia a los consumidores.

Por lo anterior, resulta necesario comenzar a abordar esta problemática a nivel nacional, delimitando los distintos ámbitos de protección de los consumidores. Para abordar la problemática planteada, el enfoque metodológico a utilizar será el dogmático, contrastando la doctrina especializada sobre la materia con la legislación vigente; así como el histórico, específicamente a propósito de las sucesivas reformas que han configurado la actual legislación antimonopólica. De esta manera, diferenciaremos según si la protección a los intereses de los consumidores es diferida por los distintos cuerpos normativos de forma directa o indirecta (o ambas a la vez), analizando doctrina y jurisprudencia nacional recaída sobre cada uno de los cuerpos normativos identificados, e indagando en la historia fidedigna del establecimiento de las normas. Sobre esta base, y como tendremos ocasión de concluir en la última parte de este trabajo, es posible sostener que el bienestar del consumidor no forma parte de la tutela dispensada por el bien jurídico libre competencia en la legislación antimonopólica.

\section{Diversas esferas de protección de los consumidores}

Los intereses de los consumidores se encuentran tutelados en diversas normativas sectoriales que forman parte del orden público económico. Específicamente, por los cuerpos normativos sobre protección de los derechos de los consumidores, consagrados en la Ley Nº 19.946 de 1997 (LPC); sobre competencia desleal, consagrados en la Ley $\mathrm{N}^{\circ} 20.169$ de 2007 (LCD); y por la normativa antimonopólica, consagrada en el Decreto Ley N 211 de 1973 (DL 211). Sin embargo, y como se mostrará a continuación, es distinto el protagonismo que estas normativas ofrecen a los consumidores en su bienestar, lo cual se traduce, en último término, que sólo en ciertos casos el bienestar de los consumidores forma parte del bien jurídico tutelado por la norma.

\subsection{Tutela del consumidor en las normas protectoras de la relación de consumo: tutela directa}

La protección jurídica de los intereses de los consumidores (colectivos y difusos), nace a consecuencia de la transformación que la sociedad ha experimentado a partir de la Segunda Guerra Mundial, siendo el derecho estadounidense el pionero en plasmar la defensa de los consumidores, en un movimiento que comenzó en 1962.

\footnotetext{
Estimamos que la expresión correcta para referirse a la preceptiva que regula la libre competencia es la de derecho a la competencia, y no otras como «derecho de la competencia» o «derecho de la libre competencia» pues, la libre competencia es una entelequia que no es, en tanto tal, sujeto ni objeto de derechos, ni privados ni públicos. En cambio, los derechos públicos subjetivos se dispensan a los incumbentes, actuales o potenciales, que se desenvuelven en cada mercado relevante; quien tienen, en consecuencia, derecho a la libre competencia en dichos mercados.
} 
En Chile, solo con la LPC se establecen normas sobre la protección de los derechos de los consumidores, teniendo por objeto este cuerpo normativo «normar las relaciones entre proveedores y consumidores, establecer las infracciones en perjuicio del consumidor y señalar el procedimiento aplicable en estas materias» (artículo $1^{\circ}$ de la LPC). Algunos autores consideran que este cuerpo normativo tiene por objeto proteger a los consumidores y usuarios ante la vulnerabilidad que ellos tienen frente a los proveedores, confiriéndoles a los primeros un conjunto de derechos a fin de que puedan llevar a cabo, en mejores condiciones, su vinculación con los segundos. ${ }^{3}$

Esta visión eminentemente protectora, que se basa exclusivamente en el sustrato fáctico de conflicto entre consumidores y proveedores, ha sido también compartida en parte de la jurisprudencia. Al efecto, es posible hacer referencia a una sentencia del Tribunal Constitucional, en que se señaló que:

«Dicha normativa se funda en la constatación de las desigualdades o asimetrías presentes en la relación de consumo entre una y otra parte, principalmente traducidas en su diferente nivel de información sobre los bienes o servicios a contratar, en su dispar capacidad negocial y en las distintas dificultades que enfrentan al momento de hacer efectivos sus respectivos derechos. Por ello es que el legislador, en este ámbito de regulación, se ha orientado por un predicamento tuitivo de los intereses de la parte más débil o desfavorecida de la relación jurídica, vale decir, el consumidor, lo que imprime a esta normativa un marcado sello tutelar o protector, y de allí la denominación que ha recibido como disciplina jurídica». ${ }^{4}$

El problema de esta mirada es que una vez que se acepta el paradigma de la protección sustentando exclusivamente en la asimetría de facto, es muy difícil evitar la salida del derecho del consumo fuera de la concepción tradicional, considerando como parte débil de la relación a pequeños empresarios. ${ }^{5}$ Por ello, denominar al cuerpo normativo de la LPC como «derecho de los consumidores» o «derecho del consumo» no es simplemente una cuestión de nomenclatura, pues en el primer caso el cuerpo normativo se entiende inspirado en un principio de favor debilis, conforme al cual la interpretación e integración normativa debe encontrarse informada y orientada hacia tal directriz; bajo la segunda, en cambio, se alude a un aspecto objetivo de la problemática, poniendo en un primer plano la tutela del mercado de consumo considerado en su integridad. ${ }^{6}$

Ahora bien, más allá de la discusión en torno a si se debe superar a nivel dogmático el enfoque "conflictivo" del derecho del consumidor, ${ }^{7}$ lo cierto es que indiscutiblemente los consumidores están directamente tutelados por dicho orden sectorial. En otras palabras, los consumidores constituyen el bien jurídico tutelado, pues hay una identidad entre bien jurídico a proteger y consumidores; a los que se les resguarda otorgándole derechos e imponiéndole deberes básicos. Esta conclusión no se afectada por la circunstancia de que otros cuerpos normativos puedan, aunque tutelando bienes jurídicos indiscutiblemente diversos, contribuir a reforzar la protección de los consumidores, ${ }^{8}$ como ocurre con la legislación antimonopólica. ${ }^{9}$

\footnotetext{
Sandoval (2004) p.59. En el mismo sentido, se ha afirmado que este cuerpo normativo es protector de la parte más débil que nace como un estatuto jurídico en una hipótesis de asimetría contractual. Narváez (2014) p.23.

$4 \quad$ Tribunal Constitucional en Requerimiento de inaplicabilidad presentado por Universal Agencia de Turismo Limitada, respecto del artículo 43 de Ley 19.496, sobre protección de los derechos de los consumidores (2008), considerando noveno.

Morales (2017) p.329.

Isler (2019) pp.41-43.

Alvear (2017) p.175.

Isler (2019) p.81.

López (1999) p.52.
} 
Realidad normativa que se puede apreciar, sin posibles dobles interpretaciones, a lo largo de los distintos párrafos del Título II de la LPC: «Los derechos y deberes del consumidor» (párrafo $2^{\circ}$ ), «de las organizaciones para la defensa de los derechos de los consumidores» (párrafo $2^{\circ}$ ), «obligaciones del proveedor» (párrafo $3^{\circ}$ ), «normas de equidad en las estipulaciones y en el cumplimiento de los contratos de adhesión» (párrafo $4^{\circ}$ ) y «responsabilidad por incumplimiento» (párrafo $5^{\circ}$ ).

Aunque excedería el propósito de este trabajo efectuar un análisis pormenorizado de dichas normas, si es necesario dejar en claro que la tutela directa que se le dispensa a los consumidores por la LPC no cubre todos los ámbitos de bienestar de este grupo. En efecto, existen otras esferas de protección de los consumidores que son dispensadas directa o indirectamente por las normas sobre la competencia desleal, y otras, que pueden quedar cubiertas indirectamente por las normas antimonopólicas.

Antes de continuar, conviene precisar esta última afirmación con un ejemplo concreto. Dentro del conjunto de ilícitos contra el bien jurídico libre competencia, existe un ilícito de abuso denominado como precios predatorios, que consiste básicamente en que el agente económico predador de precios, que cuenta con poder de mercado suficiente como para soportar una baja en los precios por un período determinado de tiempo, baja sus niveles de precios durante el tiempo suficiente como para desplazar a sus competidores, recuperando las pérdidas (o pudiendo recuperarlas) en el corto plazo. Este ilícito merma el bienestar del consumidor (si se concreta el desplazamiento de competidores) o, a lo menos, amenaza dicho bienestar (en caso de no verificarse el desplazamiento de los competidores en el mercado), pues la salida de competidores eficientes producto de un actuar ilícito altera el nivel de precios derivado de un proceso competitivo, y ello repercute naturalmente en el bienestar de los consumidores que participaban directamente en ese mercado o en mercados conexos al mismo.

Aunque pudiese pensarse apresuradamente que el ilícito en comento protege a los consumidores directamente en su bienestar, ello no es más que una apariencia producto de una conclusión prematura. En efecto, en los casos de predación el reproche de las normas antimonopólicas al predador viene aparejado por provocar la salida de competidores eficientes; alterando, con ello, el resultado del proceso competitivo. Y este reproche al injusto de monopolio se impone no solo frente a la efectiva lesión al bien jurídico libre competencia (que trae como consecuencia necesaria una pérdida de bienestar del consumidor), sino que además, frente a la puesta en peligro de este bien jurídico por parte del predador.

En efecto, conforme a la prescripción del artículo $3^{\circ}$ del DL 211, los ilícitos monopólicos contra el bien jurídico libre competencia, se castigan no solo en la hipótesis de resultado o efectiva lesión, sino que además, en la hipótesis de puesta en peligro. ${ }^{10}$ Tipificación que legitima castigar al predador incluso cuando su baja del precio no logra desplazar a sus competidores eficientes. En el caso planteado encontramos una clara hipótesis de un acto que se erige como un injusto contra el bien jurídico libre competencia y, al mismo tiempo, significa un aumento en el bienestar del consumidor, que ve aumentada su capacidad de consumo frente a la baja temporal de precios por el predador; hipótesis que no podría tener lugar si la tutela al bienestar de los consumidores se dispensase directamente por la normativa antimonopólica.

Bien puede observarse, entonces, que la normativa protectora de los derechos de los consumidores (LPC), aunque complementada y reforzada por normas reguladoras del mercado, no comparten, por esta circunstancia, la tutela de un idéntico bien jurídico. Es más, incluso en un escenario en que pudiesen cumplirse todos y cada uno de los presupuestos de una competencia perfecta —escenario incompatible

10 La referida normativa castiga a «el que ejecute o celebre, individual o colectivamente cualquier hecho, acto o convención que impida, restrinja o entorpezca la libre competencia, o que tienda a producir dichos efectos (...)» (inciso primero del artículo $3^{\circ}$ del DL 211). 
con atentados contra la libre competencia-, puede lesionarse el bien jurídico tutelado por la LPC, como, por ejemplo, la seguridad en el consumo; pues ni siquiera la estructura de mercado de competencia perfecta, ${ }^{11}$ que es una situación de hecho e hipotética, podría asegurar a los consumidores derechos que solo encuentran su fundamento y existencia en un resguardo normativo, como lo es el derecho subjetivo que la LPC confiere a los consumidores para la seguridad en el consumo de bienes o servicios, la protección de la salud y el medio ambiente y la evitación de riesgos que puedan afectarles (literal d) del artículo $3^{\circ}$ de la LPC). Por esta razón, no podemos concordar con la doctrina que sostiene que las políticas de protección al consumidor serían innecesarias frente a un escenario de competencia perfecta. ${ }^{12}$

\subsection{Tutela del consumidor en las normas de competencia leal: tutela directa e indirecta}

Al examinar la LCD, aunque parte su articulado situando expresamente a los consumidores como sujetos de la tutela dispensada por este cuerpo normativo (artículo $1^{\circ}$ de la LCD), al prescribir que dicha ley «tiene por objeto proteger a competidores, consumidores y, en general, a cualquier persona afectada en sus intereses legítimos por un acto de competencia desleal»; continuando la lectura de sus normas, en seguida, pareciese limitarse por el mismo cuerpo normativo el ámbito de aplicación solo a las situaciones en que existe una relación de competencia susceptible de desviar clientela. En efecto, prescribe el artículo $3^{\circ}$ de la LCD que, en general: «es acto de competencia desleal toda conducta contraria a la buena fe o a las buenas costumbres que, por medio ilegítimos, persiga desviar clientela de un agente del mercado».

Mientras que algunos autores concluyen que de las normas antes transcritas debe entenderse que la tutela solo se dispensa entre competidores en una relación horizontal (que son los únicos capaces de desviar clientela de otro agente de mercado), ${ }^{13}$ otros participan de una opinión diversa, y sostienen que se aplica a todo agente regulado en el artículo $1^{\circ}$ de la LCD que concurre en el mercado. ${ }^{14}$ Nosotros participamos de esta última doctrina, por cuanto una recta interpretación, conforme a criterios históricos y lógicos, solo puede llevar a concluir que la relación de competencia no es una condición necesaria para acceder a la tutela de la LCD $;^{15}$ consecuentemente, esta preceptiva resulta aplicable «tanto a los competidores en sus relaciones recíprocas como entre los competidores y los consumidores». ${ }^{16}$

Entonces, es posible afirmar que la LCD dispensa tutela indirecta a los consumidores en aquellos casos en que regula las relaciones horizontales entre competidores sobre la base de una relación de competencia, pues los consumidores mismos son la "clientela desviada» a la que se refiere el artículo $3^{\circ}$ de la LCD; pero también dispensa este cuerpo normativo tutela directa a los consumidores, en tanto tales, por la sola circunstancia de concurrir al mercado de bienes y servicios.

Los economistas tradicionalmente han identificado como presupuestos copulativos de una situación de competencia perfecta la concurrencia de cuatro condiciones: (i) existencia de un elevado número de compradores y vendedores en el mercado; (ii) que tanto compradores como vendedores deben ser indiferentes respecto a quién comprar o vender; (iii) que todos los compradores y los vendedores tengan un conocimiento pleno de las condiciones generales del mercado, y; (iv) la libre movilidad de los recursos productivos, Larroulet y Mochón (1996) pp.182-183. Pero, incluso, ni los economistas que estiman que las anteriores condiciones no son ni necesarias ni suficientes para que la economía produzca un ambiente perfectamente competitivo Vial y Zurita (2011) p.223, agregan como condiciones situaciones de hecho que aseguren derechos subjetivos a los consumidores, tales como la seguridad en el consumo, su derecho a la reparación e indemnización adecuada y oportuna o la educación para un consumo responsable.

12 Isler (2019) p.75. Con mayor razón, y por los mismos fundamentos, no podemos concordar con la doctrina que afirma que la regulación del consumo busca que se garantice el cumplimiento de las condiciones para que los mercados operen en forma eficiente en un esquema óptimo de fijación de precios Mardones (2020) p.195. Ambas posiciones confunden las estructuras de mercado, ideales o reguladas, con los derechos subjetivos públicos creados, o reconocidos, por las normas jurídicas.

13 Tapia (2008) p.3.

14 Contreras (2012) p.98.

15 Bernet (2014) pp.418-424.

16 Contreras (2012) p.102. 


\subsection{Tutela del consumidor en las normas antimonopólicas: tutela indirecta}

El derecho a la competencia actúa de dos formas para cautelar el proceso competitivo. Una primera forma de actuación tiene lugar en la denominada política estructural o ex ante, en que el derecho a la competencia reacciona preventivamente para evitar el surgimiento de estructuras de mercado que podrían dañar o poner en peligro el bien jurídico tutelado $;{ }^{17}$ para ello, las autoridades de libre competencia deben sopesar los posibles riesgos u eficiencias derivados de las operaciones de concentración.

La segunda forma de actuación de la normativa antimonopólica, es la denominada política de comportamiento o actuación ex post, en que las autoridades de libre competencia movilizan sus recursos de forma represiva para sancionar posibles afectaciones al bien jurídico tutelado. En este ámbito, la barrera de punibilidad o sanción de los ilícitos infraccionales se encuentra adelantada, pudiendo sancionarse no solo las afectaciones efectivamente concretadas contra el bien jurídico, sino que también la sola puesta en peligro de dicho bien. Es más, tras la reforma legislativa introducida al Decreto Ley $\mathrm{N}^{\circ} 211$ de 1973 por la Ley $\mathrm{N}^{\circ} 20.945$ de 30 de agosto de 2016, incluso podría ser posible la sanción de ciertas conductas sin sujetarse a una hipótesis de peligro. Las reflexiones que se efectuarán en las páginas siguientes, son en torno a esta última política de libre competencia.

En Chile, los primeros intentos por proteger al consumidor por la vía de la regulación económica del mercado, provinieron de los esfuerzos desplegados bajo la segunda presidencia de Carlos Ibáńez del Campo (1952-1958), oportunidad en que el ejecutivo, con miras a modernizar el sistema de ingresos fiscales, contrató una misión de expertos de las Naciones Unidas (Misión Klein-Saks) para colaborar con el Gobierno en el estudio y preparación de un conjunto de medidas financieras y económicas para el país. ${ }^{18}$ Dentro de estas medidas coadyuvadas por la Misión Klein-Saks, consta en la historia legislativa un Proyecto de Ley de 1957, en cuyo mensaje presidencial se dejó expresa constancia de la intención de obtener el desarrollo de las actividades económicas con el fomento de la libre iniciativa, con la supresión de los privilegios y con la libre competencia.

En este Proyecto de Ley se dejó, además, expresa constancia que con la consecución de estos fines legislativos resultaría efectivamente beneficiado el consumidor y se obtendría paulatinamente una elevación del estándar de vida de todos los habitantes del país. ${ }^{19}$ Es decir, el ejecutivo de ese entonces tenía absoluta claridad en torno a que el fomento de la libre iniciativa a través de la protección de la libre competencia, conlleva un favorecimiento indirecto (tutela indirecta) tanto de los consumidores como de los habitantes en general. Por lo demás, así lo expresó claramente el presidente Ibáñez en su Cuenta Pública de 1957, en que anunció un proyecto de ley antimonopolios que redundaría en beneficio de los consumidores y un aumento de la productividad. ${ }^{20}$

Sin embargo, en esta materia los esfuerzos legislativos solo se plasmaron en la promulgación de un texto legal bajo la presidencia de Jorge Alessandri Rodríguez (1958-1964), con la dictación de la Ley Nº 13.305

\footnotetext{
Hernández e Hidalgo (2018) p.91.

8 Bernedo (2013) p.29.

19 Literalmente, el mensaje presidencial del Proyecto de Ley de 1957 se refería a que « (...) el proyecto de ley que se propone busca obtener el desarrollo de las actividades económicas con el fomento de la libre iniciativa, con la supresión de los privilegios y con la libre competencia, para que así resulte efectivamente beneficiado el consumidor y se obtenga paulatinamente una elevación real del estándar de vida de todos los habitantes del país.»

20 Biblioteca del Congreso Nacional, mensajes de S.E. don Carlos Ibáńez del Campo, al Congreso Nacional al inaugurar el período ordinario de sesiones. 21 de mayo de 1957, p. 34. Disponible en: https://www.bcn.cl/obtienearchivo?id=documentos/10221.1/65086/1/Cuenta_publica_Hacienda_1957.pdf
} 
de 6 de abril 1959, en que, por primera vez en Chile, se sancionaron los actos o convenciones tendientes a impedir la libre competencia (artículo 173).

Al analizar la historia de la Ley $\mathrm{N}^{\circ} 13.305$, a diferencia del intento legislativo anterior del presidente Ibánez, es posible concluir que se comienza a difuminar la línea divisoria entre la tutela de la libre competencia y la tutela de los consumidores. En efecto, en el Mensaje presidencial se dejó constancia de que el objetivo de la normativa es el asegurar que la empresa privada pudiese proteger efectivamente el interés de los consumidores, pero también se afirmó que la esencia de la libre competencia es la protección del emprendimiento (instalación de nuevos negocios). ${ }^{21}$

La discusión parlamentaria poco aportó para delimitar los ámbitos de protección y, por el contrario, acentuó la difuminación de bienes jurídicos protegidos. ${ }^{22}$ Sin embargo, en algunas intervenciones se dejó constancia que la libre competencia se lograba a través de una real y verdadera libre concurrencia, y que por medio de esta tutela, se dispensa protección tanto a los consumidores como al desenvolvimiento económico de la producción. ${ }^{23}$

Finalmente, toda la historia legislativa de protección a la libre competencia en Chile desemboca en el Decreto Ley No 211 de 1973, acto refundacional en que la Junta de Gobierno fijó normas para la defensa de la libre competencia, teniendo presente que: (i) el monopolio y las prácticas monopólicas son contrarias a una sana y efectiva competencia en el abastecimiento de los mercados, ya que mediante el control de la oferta o demanda es posible fijar precios artificiales y lesivos al interés del consumidor; (ii) tales actividades, por otra parte, no incentivan la producción; protegen al productor o distribuidor ineficiente; tienden a la concentración del poder económico y distorsionan el mercado en perjuicio de la colectividad, y; (iii) por tanto, resulta necesario garantizar la libre concurrencia previniendo la existencia del monopolio y de las prácticas monopólicas y sancionando drásticamente su ejecución.

Del mensaje del ejecutivo en diciembre de 1973 puede desprenderse, entonces, la identificación del bien jurídico libre competencia con la libre concurrencia en un mercado no distorsionado ${ }^{24}$ de cuya protección se logra también la consecución de otros bienes jurídicos socialmente relevantes, como lo son el consumidor —entendido, incluso, como la colectividad-y el incentivo de la producción. Se trata de una proclamación legislativa muy similar a la de su homólogo en 1957 que, como ya se mencionó,

21 «(...) bajo el amparo de los precios oficiales ha sido posible llegar a entendimientos entre los productores y comerciantes de un mismo rubro, de manera que los precios quedan fijados por productores de mayor costo. Para que la empresa privada defienda efectivamente el interés del consumidor es indispensable que los productores y distribuidores estén preocupados de reducir sus costos impulsados constantemente por una sana y efectiva competencia en el abastecimiento de los mercados (...) Se considera que la libertad para la instalación de los nuevos negocios es la esencia misma de la libre competencia.»

22 «Diputado Eluchans: Por eso nosotros defendemos el concepto de la libre empresa. Defendemos la idea de la libertad económica y sostenemos que el Estado no puede renunciar a su derecho fundamental de proteger al consumidor, de llegar hasta aquellos que viven de un sueldo o un salario, a fin de impedir que sean expoliados por empresas - a través de carteles, de sistemas de producción artificial o por cualquier otro arbitrio, que son muchos, porque la imaginación humana es inagotable— que tienden, precisamente, a abusar de los consumidores (...).»

23 «Diputado Diez: Terminé, refiriéndome a la protección del consumidor por medio de, la libre empresa, manifestando que el criterio del Ejecutivo era que la mejor defensa de aquél se lograba precisamente a través del establecimiento de una real y verdadera libre concurrencia, sin vicios de este sistema, como son los monopolios, los carteles o "trusts", que, evidentemente, no solo perjudican al consumidor, sino que, también, al desenvolvimiento económico de la propia producción.»

24 Aunque de una primera lectura del mensaje de 1973 podría existir una inclinación a concluir que esta tutela de la libre concurrencia en un mercado no distorsionado debería ser complementada con el rechazo de los monopolios y los mercados concentrados en general, una lectura más detenida de mensaje — y que tenga presente los postulados de la teoría económica — nos lleva a abandonar esa inclinación; es claro que el reproche a estructuras de mercado oligopólicas o monopólicas solo tiene sentido cuando son alcanzadas o mantenidas por competidores ineficientes que las logran por medio del ejercicio de actividades al margen de la ley. En otras palabras, cuando los agentes económicos por medios lícitos en base al desarrollo de eficiencias (competencia en los méritos) alcanzan una estructura de mercado oligopólica o monopólica y desplazan a competidores ineficientes, no pueden ser objeto de reproche, del mismo modo que los monopolios legales. Conclusión que es coincidente con este mismo mensaje de 1973, en que se hace referencia a los competidores ineficientes y a la existencia de monopolios legales. 
identificó la tutela de la libre competencia con la protección de la libre iniciativa y, por su intermedio, de otros bienes jurídicos socialmente relevantes, como los consumidores y el aumento de la productividad.

Con posterioridad, el DL 211 fue modificado por la Ley 19.610 de 1999, que fortaleció las atribuciones de la Fiscalía Nacional Económica. En el Mensaje presidencial del proyecto de ley que originó la referida reforma legislativa, se dejó en claro que el bien jurídico protegido por la legislación de libre competencia no es la libertad del consumidor (ni del vendedor), y que, por lo mismo, el reproche de los ilícitos monopólicos no requiere la verificación de perjuicios al consumidor. Y en un intento por delimitar la libre competencia, el Ejecutivo hizo referencia a que esta tutela significa la protección de la posibilidad de cualquier persona de ingresar al mercado (lo que configura un requisito básico del ideal económico de competencia perfecta) $)^{25}$, agregado durante la discusión parlamentaria que, en la medida en que los mercados operen bien y de manera transparente, los beneficios se trasladan a los consumidores. ${ }^{26}$

Más tarde, con la Ley $\mathrm{N}^{\circ} 19.911$ de 2003, que modificó el DL 211 creando el Tribunal de Defensa de la Libre Competencia, el Ejecutivo de ese entonces buscó consagrar normativamente el bienestar de los consumidores como un fin de las normas antimonopólicas, proponiendo en su mensaje comenzar el articulado con la siguiente prescripción: «La presente ley tiene por objeto defender la libre competencia en los mercados, como medio para desarrollar y preservar el derecho a participar en las actividades económicas, promover la eficiencia y, por esta vía, el bienestar de los consumidores». ${ }^{27}$ Propuesta que fue enderezada en durante la discusión parlamentaria, en que se decidió suprimir la referencia al bienestar de los consumidores. Al respecto, es especialmente clarificadora la intervención del senador Novoa, quien expresó:

«Lo que se planteó como tema por discutir y clarificar es la referencia al bienestar de los consumidores, pues existen una legislación y un marco regulatorio, que es precisamente la defensa de los derechos del consumidor, que tiene un ámbito de aplicación específico y distinto del de una ley de defensa de la libre competencia [...] si el objeto es muy amplio, podría darse el caso de que alguien recurriera al Tribunal de Defensa de la Libre Competencia para defender, por ejemplo, bienes jurídicos amparados por la Ley sobre Protección de los Derechos de los Consumidores». ${ }^{28}$

Sin embargo, pese a que el mensaje hacía referencia expresa al bienestar de los consumidores (propuesta desechada), no cabe afirmar un cambio en la tendencia legislativa del Ejecutivo en orden a considerar que el bienestar de los consumidores es solo una consecuencia (mediata), entre otras, de la protección del bien jurídico libre competencia. Esto queda en evidencia en la precisión del mismo Ejecutivo frente a la propuesta del senador García, que propuso reemplazar el inciso primero, manifestando que la ley defenderá la libre competencia en los mercados como medio para desarrollar y preservar el bienestar de los consumidores $^{29}$. Oportunidad en que el Ejecutivo fue claro en señalar que la propuesta del senador García «altera completamente la finalidad de la ley. El propósito de ésta es la defensa de la libre competencia, para lo cual el elemento central es la participación de las personas en las actividades económicas. En ese marco, la eficiencia y el bienestar de los consumidores son fines eventuales y mediatos». ${ }^{30}$

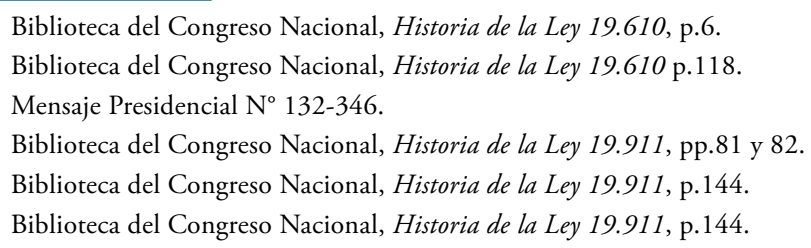


En definitiva, durante el tercer trámite constitucional, la Comisión Mixta —a propuesta del senador Parra- optó por suprimir toda referencia al bienestar de los consumidores dentro de la limitación del bien jurídico tutelado, entregando el desarrollo conceptual de este bien jurídico al trabajo de la doctrina y jurisprudencia. ${ }^{31} \mathrm{Al}$ desarrollo de este trabajo encomendado por el legislador nos referiremos a continuación.

\subsubsection{Jurisprudencia y doctrina tradicional sobre el rol del bienestar de los consumidores dentro de la tutela de la libre competencia}

Como fluye de la historia fidedigna de la actual regulación del DL 211, el legislador antimonopólico prefirió no entregar una conceptualización normativa de libre competencia, entregando el desarrollo del concepto a la doctrina y jurisprudencia. ${ }^{32}$ Este redireccionamiento de la problemática, a lo menos en su concepción tradicional, no tuvo la virtud deseada por el legislador.

En efecto, han existido importantes aportes doctrinales para llenar este vacío, tomando como propio el trabajo encomendado por el legislador, sosteniéndose que la libre competencia es un bien jurídico protegido de aquellos denominados públicos, que dice relación del funcionamiento de un sistema que promueve una forma de orden social mediante la cual se armoniza el ejercicio de la libertad de competencia mercantil por parte de todos los ciudadanos que la ostentan. ${ }^{33}$ Pero también, han existido otros tantos aportes que más que llenar el vacío entregado por le legislador, han confundido las instituciones del derecho a la competencia. ${ }^{34}$

Y quizás por influencia de estas últimas doctrinas, la jurisprudencia de la Corte Suprema ha también confundido las instituciones y el objeto de la tutela. En efecto, por una parte ha resuelto:

"Que es importante destacar que las prácticas de competencia desleal son sancionables en sede de libre competencia cuando el agente-que es un partícipe del mercado- busca lograr, mantener o incrementar una posición de dominio. Ello se debe a que el derecho de la competencia tiene como objetivo primordial neutralizar posiciones de poder de mercado de los agentes económicos y, en tal sentido, se aspira a mantener un orden en que la libertad económica se presenta como un medio a través del cual se consolida el bienestar de la Nación (...)». ${ }^{35}$

Por otra parte, y lo que nos centra en los esfuerzos de las páginas siguientes, la Corte Suprema ha sostenido que el bien jurídico libre competencia se identifica con el bienestar de los consumidores. En efecto, ha

31 Las Comisiones Unidas debatieron ampliamente el tema, optando por aprobar la indicación del senador Parra por entregar un concepto mucho más simple que, sin definir la libre competencia, se inclina por establecerla solamente como bien jurídico protegido, confiando la expresión de su alcance a la doctrina y la jurisprudencia (Biblioteca del Congreso Nacional, Historia de la Ley 19.911, p. 144).

32 Biblioteca del Congreso Nacional, Historia de la Ley 19.911, p. 144)

33 Valdés (2006) p.188.

34 Así, por ejemplo, se ha afirmado que «El derecho de la libre competencia tiene por objeto neutralizar posiciones de poder de mercado y, en tal sentido, forma parte de la constitución económica de un orden basado en la libre elección de los consumidores» Barros (2007) p.1042, en circunstancia de que el derecho antimonopólico dista mucho de esa función, quizás más propia de los sistemas de economía centralizada. La normativa de libre competencia busca, en cambio, dentro de otros fines, neutralizar las posiciones de mercado ilegítimamente alcanzadas, mantenidas o acrecentadas.

35 Corte Suprema en Beatriz Lea Zuberman Comercializadora E.I.R.L. con One Smart Star Number Chile S.A. (2014), considerando noveno. Como se dijo en la nota anterior, las posiciones de dominio legítimamente alcanzadas y ejercidas no son merecedoras de reproche en sede de libre competencia. Incluso, desde el punto de vista del proceso competitivo, es deseable que los agentes económicos ineficientes sean desplazados del mercado y, por ello, no son sujetos de tutela. Ello es entendible, por cuanto, la libre competencia no tutela a los competidores y, en este sentido, tampoco es un fin de la institucionalidad de la libre competencia tutelar el ingreso de nuevos competidores por el solo hecho de incrementar el número de participantes en el mercado (Tribunal de Defensa de la Libre Competencia en Demanda de Netline Mobile S.A. contra Entel PCS Telecomunicaciones S.A. y otros (2017), consideración nonagésimo octavo). 
sostenido que los fines que respaldan la libre competencia son el derecho a participar en las actividades económicas, la eficiencia y el bienestar de los consumidores, que es la razón final de la regulación económica. ${ }^{36}$

Esta interpretación de nuestro máximo tribunal, que se ha venido reiterando en su última jurisprudencia, no encuentra asidero ni en criterios históricos — como ya se ha detallado-, ni en ningún elemento interpretativo. Este yerro hermenéutico, como lo evidenciaremos a lo largo de los párrafos siguientes, no envuelve una interpretación extensiva que dispense una mayor protección a los consumidores. Muy por el contrario, es una interpretación desprotectora del consumidor, pues los intereses difusos y colectivos de los consumidores, en tanto intereses y no un mero bienestar material en un momento dado, encuentran una mayor y mejor complementación en los resguardos de la normativa antimonopólica, solo si se supera el yerro hermenéutico que identifica el bien jurídico libre competencia con el bienestar del consumidor; concepto que es incapaz de capturar todos los intereses de los consumidores, pues los intereses del consumidor no se reducen únicamente a costos (bienestar del consumidor en sentido estricto), sino que además, contempla la calidad de los productos, la variedad y la innovación. ${ }^{37}$

\subsubsection{Tutela indirecta a los consumidores mediante la protección del proceso competitivo}

Aunque de la revisión de los antecedentes históricos y jurisprudenciales no se extraen conclusiones unívocas en torno al rol del bienestar de los consumidores dentro del sistema de protección de la libre competencia, estimamos que resulta forzoso concluir que la ley antimonopólica tutela directamente el proceso competitivo y, por esa vía, la mayor de las veces — pero no siempre ni necesariamente - tutela indirectamente otros bienes jurídicos, dentro de ellos, el bienestar de los consumidores, la protección del emprendimiento y el aumento de la productividad.

En otras palabras, la falta de afectación al bienestar de los consumidores no tiene relevancia típica en la configuración de un ilícito monopólico, como si la tiene la falta de afectación del proceso competitivo, que es un requisito de toda infracción a la libre competencia. Sin embargo, la mayor o menor afectación al bienestar del consumidor si tiene virtud modificatoria de la responsabilidad infraccional, atenuándola o agravándola, toda vez que encierra un mayor disvalor, y por tanto merece un mayor reproche, el ilícito monopólico que en su configuración disminuye el bienestar de los consumidores.

Nuestra conclusión encuentra pleno sustento en la actual regulación de libre competencia, de cuyas normas se desprende necesariamente la existencia de ilícitos monopólicos cuya configuración y verificación lesionan o ponen en peligro el proceso competitivo, pero sin altera el bienestar de los consumidores; ni por su efectiva afectación (ilícitos monopólicos de resultado) ni por su puesta en peligro (ilícitos monopólicos de peligro). Estos ilícitos monopólicos — que afectan el proceso competitivo sin alterar el bienestar de los consumidores - se puede enmarcar en la descripción típica de la norma del inciso primero del artículo $3^{\circ}$ del DL 211, como es el caso del ilícito de incumplimiento de resoluciones de la autoridad o del ilícito de explotación abusiva de una relación de dependencia económica; o bien, enmarcarse en la descripción típica de las prescripciones de los distintos literales del inciso segundo del mismo artículo.

\footnotetext{
36 Corte Suprema en Corporación Nacional de Consumidores y Usuarios de Chile con Movistar S.A., Claro Chile S.A. y Entel PCS S.A. (2016), consideración cuarta.

$37 \quad$ Khan (2017) p.737.
} 
En cuanto a esto último, un claro ejemplo es un cartel de precios en que todos los competidores con una finalidad altruista (como la existencia de una catástrofe natural), y sin aptitud objetiva predatoria, se concierta para bajar los precios de un bien o servicio por debajo del nivel competitivo. Una conducta como la descrita, aunque incluso aumenta el bienestar de los consumidores, merece todo el reproche de las normas antimonopólicas, pues la pérdida de independencia en la toma de decisiones empresariales por parte de los competidores lesiona el bien jurídico tutelado por la libre competencia: el proceso competitivo. ${ }^{38}$

Pese a lo dicho, debe reconocerse que la mayor de las veces la tutela del proceso competitivo en esta sede viene acompañada de la tutela del bienestar de los consumidores, así como también, de la tutela del emprendimiento, de la productividad y de otros bienes jurídicos socialmente relevantes. Pero de la normalidad estadística no se desprende el thelos de las prescripciones normativas, sino que, en cambio, éste se obtiene - ante el silencio en la historia fidedigna — de en una enderezada interpretación hermenéutica de las palabras de la ley, que permita dar coherencia al cuerpo legal.

De esta manera, no es posible compartir la doctrina y jurisprudencia que identifica el bienestar del consumidor como la finalidad de las normas protectoras de la libre competencia; no obstante compartir ambas regulaciones su raíz común de pertenencia al orden público económico. ${ }^{39}$ En cambio, compartimos la doctrina y las decisiones de las autoridades antimonopólicas, administrativas y judiciales, que identifican en la libre competencia un bien jurídico distinto y distinguible del bienestar de los consumidores.

En doctrina, son lúcidas las conclusiones — y se comparten — del profesor Julio Alvear, para quien para quien la libre competencia es un instituto jurídico que asegura la justicia del mercado, sin afectar su eficiencia. ${ }^{40}$ Igualmente acertada es la jurisprudencia administrativa de la Fiscalía Nacional Económica que sostiene que «el bien jurídico protegido por el Derecho de la Competencia no es la protección de los competidores ni de los consumidores, sino la competencia misma». ${ }^{41}$

Por su parte, la jurisprudencia del Tribunal de Defensa de la Libre Competencia también se ha distanciado de la identificación del bienestar del consumidor con el objeto y fin de la tutela de las normas antimonopólicas. Así, ha fallado el Tribunal de Defensa de la Libre Competencia que la protección se identifica con el proceso competitivo y la incertidumbre que le es propia:

«Que de lo razonado en las consideraciones anteriores, este Tribunal concluye que efectivamente los representantes de la totalidad de las líneas de buses urbanos para transporte de pasajeros de la ciudad de Osorno suscribieron, con fecha 27 de noviembre de 2007, una serie de acuerdos que, según su tenor,

38 En cambio, de adherir a una tesis que concluya el bien jurídico tutelado por la libre competencia es el bienestar de los consumidores, la conclusión en el caso propuesto debería ser que un acuerdo de precios entre competidores, sin aptitud objetiva predatoria, para posicionar el precio a un nivel infra competitivo, no es en caso alguno reprochable por las normas sancionatorias. La falta de reproche también se extendería a otros tantos casos, como el incumplimiento de resoluciones de la autoridad, conducta que no desafía el bienestar del consumidor, sino que, en cambio, la vigencia comunicativa de la decisión de la autoridad. Del mismo modo, quedaría impune la explotación abusiva de una relación de dependencia económica, que solo desafía el bienestar del agente económico dependiente abusado, más no el bienestar de los consumidores.

39 Yrarrázaval (1999) p.25.

40 Alvear (2017) 121. El professor Enrique Barros, por su parte, estima que las normas antimonopólicas protegen la estructura competitiva y abierta del mercado (Barros (2010) 1043).

${ }_{41}$ Fiscalía Nacional Económica en Denuncia de particular por caso de competencia desleal. Rol $N^{\circ} 2432-17$ FNE (2017), p. 2. En el mismo sentido, el Tribunal de Defensa de la Libre Competencia ha resuelto que «En Chile, al igual que en el derecho comparado, es claro que la preocupación del derecho de la competencia no es proteger competidores, sino el proceso competitivo» (Tribunal de Defensa de la Libre Competencia en Demanda de Ramírez y Compañia Limitada contra Ministerio de Transportes y Telecomunicaciones (2014), consideración décimonovena). 
tuvieron claramente por objeto limitar en varios aspectos la libertad, autonomía e independencia empresarial de cada uno de sus suscriptores, coordinando una serie de factores de competencia en el mercado para eliminar la incertidumbre que es propia de un proceso competitivo y reemplazarla por la seguridad de la cooperación entre empresas que, dado que operan en un mercado libre y que no está mayormente regulado en materia de oferta y no lo está, en absoluto, en materia de precios -como es el del transporte público de la ciudad de Osorno en la actualidad- debiesen rivalizar por la preferencia de los usuarios del servicio que prestan». ${ }^{42}$

En el mismo sentido, ha identificado también en su jurisprudencia el daño o perjuicio al proceso competitivo en el mercado, como la afectación al bien jurídico libre competencia:

"Que, como conclusión general, la estrategia de precios y horarios analizada en esta sentencia en las consideraciones trigésimo tercera a cuadragésimo tercera y los actos de hostigamiento en contra de un rival, analizados en los razonamientos quincuagésimo segundo a quincuagésimo cuarto, no tienen sentido económico para la requerida, salvo por el objetivo de perjudicar el proceso competitivo en el mercado. En otros términos, son manifestaciones del ejercicio abusivo del poder de mercado que adquirieron los miembros de la requerida al adoptar una decisión en tal sentido en la asociación gremial que los coordina, y que busca ampliarlo y prolongarlo.

Que este Tribunal considera entonces que todas estas conductas, apreciadas individual y conjuntamente, dañaron el proceso competitivo en el mercado analizado e infringieron el artículo $3^{\circ}$ del Decreto Ley No 211, que considera ilícito todo hecho, acto o convención que impida, restrinja o entorpezca la libre competencia, razón por la cual el requerimiento dirigido en contra de la asociación en cuyo seno se adoptaron las decisiones anticompetitivas de autos, debe ser acogido en todas sus partes y ésta debe ser sancionada con la multa y las medidas que se indicarán en lo resolutivo de esta sentencia». ${ }^{43}$

También, en el mismo sentido, la jurisprudencia del Tribunal de Defensa de la Libre Competencia ha especificado que esta afectación al proceso competitivo debe tener lugar en uno o más mercados relevantes determinados. No se trata, entonces, de una afectación genérica al proceso competitivo:

"Que en lo que hace a los actos de autoridad, cabe tener presente que, cuando éstos están dirigidos a la consecución de determinados fines de política pública -por medio de la asignación de recursos o derechos, o de la imposición de gravámenes que tengan actual o potencialmente consecuencias en el desarrollo del proceso competitivo en uno o más mercados-, pueden ser eventualmente conocidos y juzgados en esta sede, con el objeto de establecer si las restricciones a la competencia que tales actos de autoridad pudiesen entrañar son susceptibles de sanción conforme al Decreto Ley No 211, o requieren del ejercicio de otras facultades de este Tribunal para la promoción de la libre competencia y la prevención de actos que puedan afectarla, como sería la proposición de modificación normativa». ${ }^{44}$

Finalmente, el Tribunal de Defensa de la Libre Competencia se ha referido a la afectación del proceso competitivo subvirtiendo su uso por parte de los agentes económicos:

42 Tribunal de Defensa de la Libre Competencia en Requerimiento de la Fiscalía Nacional Económica en contra de Transportes Central Ltda. y otros. (2010), considerando trigésimo quinto.

43 Tribunal de Defensa de la Libre Competencia en Requerimiento de la FNE contra Asociación Gremial de Dueños de Mini Buses Agmital (2010), considerando sexagésimo cuarto y sexagésimo quinto.

44 Tribunal de Defensa de la Libre Competencia en Demanda de NETLANDCHILE S.A. contra el Ministerio de Transportes y Telecomunicaciones (2010), considerando décimo séptimo. 
"Que, en primer término y como ha sido tantas veces reiterado, la colusión es el atentado más grave en contra de la libre competencia. Esto por cuanto no sólo suprime la rivalidad entre los competidores miembros del cartel, incrementando las ganancias de los oferentes y disminuyendo el beneficio de los demandantes, sino también porque subvierte el uso del proceso competitivo como mecanismo de vigilancia de las actividades en un mercado, asegurando ventajas competitivas a ciertos demandantes que de otro modo no tendrían si no fuera por la colusión existente (véase Marshall, Robert C. Y Marx, Leslie M., The Economics of Collusion: Cartels and Bidding Rings, The MIT Press, 2012, en especial pp. 83 y ss.)». ${ }^{45}$

Por lo razonado en los párrafos precedentes, la afectación al bien jurídico libre competencia se producirá siempre que se afecte, dańe o subvierta el proceso competitivo en un mercado relevante determinado, o que tienda a producir dicho efecto. Si no existe esta afectación real o, a lo menos, su puesta en peligro, no hay lesión al bien jurídico tutelado y, consecuentemente, la conducta no puede ser objeto de reproche en sede de libre competencia; exista o no disminución al bienestar del consumidor, o al bienestar de los competidores mismos.

Y no afecta a la conclusión anterior la jurisprudencia del Tribunal de Defensa de la Libre Competencia que se refiere a la libertad económica como presupuesto para el ejercicio de la jurisdicción antimonopólica, ${ }^{46}$ o la jurisprudencia que exige no poner en riesgo bienestar social; ${ }^{47}$ la libertad económica es el presupuesto de existencia de todo proceso competitivo, y el bienestar social es el efecto necesario del mismo, por el solo hecho del uso del procedimiento competitivo por parte de los agentes económicos.

\section{Comentarios finales}

Los intereses de los consumidores se encuentran tutelados directa e indirectamente en diversas normativas sectoriales que forman parte del orden público económico. De manera directa o inmediata, se encuentra tutelado por los cuerpos normativos sobre protección de los derechos de los consumidores (Ley $\mathrm{N}^{\circ} 19.946$ de 1997) y sobre competencia desleal (Ley Nº 20.169 de 2007).

La normativa antimonopólica (Decreto Ley $\mathrm{N}^{\circ} 211$ de 1973), en cambio, solo dispensa una protección indirecta o mediata a los consumidores en su bienestar, en la medida en que estos generalmente son agentes en las dinámicas propias del proceso competitivo; que son a quienes se les transfieren las eficiencias de esta dinámica en la mayor parte de los casos. Pero esta realidad económica, que se presenta en la generalidad de los procesos de intercambio, no denota la finalidad de la regulación de las normas protectoras de la libre competencia.

Tan cierto es lo anterior, que un análisis detenido de la historia de la ley protectora de la libre competencia —incluso anterior al mismo DL 211-, permite descartar claramente el bienestar de los consumidores como el bien jurídico tutelado por el derecho antimonopólico. Pero más allá de las conclusiones que

45 Tribunal de Defensa de la Libre Competencia en Requerimiento de la FNE contra CMPC Tissue S.A. y Otra (2017), considerando ducentésimo primero. Razonamiento reiterado por el Tribunal de Defensa de la Libre Competencia, entre otras, en la decisión recaída en Requerimiento de la FNE contra CCNI S.A. y otras (2019), considerando ducentésimo vigésimo sexto.

46 Tribunal de Defensa de la Libre Competencia en Demanda de Sonda S.A. contra Servicio de Registro Civil e Identificación (2013), considerando decimosexto.

47 Tribunal de Defensa de la Libre Competencia en Consulta de GLR Chile Limitada sobre la compra de la totalidad de acciones de Iberoamerican Radio Chile S.A. (2007), considerando octogésimo sexto. 
derivan del análisis de la historia legislativa de los diversos cuerpos normativos que han regulado el derecho a la libre competencia, consideraciones de orden hermenéutico llevan necesariamente al mismo resultado.

Por una parte, es posible identificar ilícitos monopólicos en que el bienestar del consumidor es ajeno a la hipótesis normativa, como ocurre en la hipótesis de abuso de dependencia económica. Por otra, y lo que resulta más claro aún, hay otras hipótesis normativas en que el bienestar del consumidor incluso puede verse permanentemente aumentado y, aún así, no eliminarse el injusto monopólico del acto, como ocurre en un acuerdo entre competidores sobre el precio a la baja sin aptitud predatoria respecto de un bien o servicio, o en el acto del predador que es sancionado bajo la hipótesis de peligro sin que hubiese alcanzado a desplazar del mercado a un competidor eficiente. Casos como estos demuestran que es compatible el injusto de monopolio y el aumento en el excedente del consumidor.

De esta manera, independientemente del bien jurídico que se considere protegido por las normas antimonopólicas — siendo el proceso competitivo al que se suscribe en este trabajo- lo cierto es que el bienestar del consumidor no forma parte del mismo; al menos, de forma inmediata. Y ello trae, también, importantes consecuencias adjetivas de cara a la posible afectación el principio de non bis in idem por la sanción infraccional de ilícitos por parte de los diversos cuerpos normativos referidos, cuando los elementos objetivos del tipo obedecen a un mismo sustrato factico.

\section{Bibliografía citada}

Aguirrezabal, Maite (2019): Defensa de los consumidores y acceso a la justicia. Un análisis del procedimiento colectivo en la legislación chilena (Santiago, Thomson Reuters).

Alvear, Julio (2017): Libertad económica, libre competencia y derecho del consumidor. Un panorama crítico (Valencia, Tirant lo Blanch).

Barros, Enrique (2010): Tratado de Responsabilidad Extracontractual (Santiago, Editorial Jurídica de Chile).

Bernedo, Patricio (2013): Historia de la libre competencia en Chile, 1959-2010 (Santiago, Fiscalía Nacional Económica).

Bernet, Manuel (2014): La presentación comercial en el derecho de la competencia desleal. Evolución en el derecho comparado y su protección en Chile (Santiago, Thomson Reuters).

Contreras, Oscar (2012): La competencia desleal y el deber de corrección en la ley chilena (Santiago, Ediciones Universidad Católica de Chile).

Hernández, Diego e Hidalgo, Beatriz (2018): ¿Por qué se aprueban tantas fusiones? Un análisis desde la perspectiva de la libre competencia de riesgos, eficiencias y medidas de mitigación, en operaciones de concentración (Santiago, Thomson Reuters).

Isler, Erika (2019): Derecho del Consumo. Nociones fundamentales (Valencia, Tirant lo Blanch).

Khan, Lina (2017): «Amazon's Antitrust Paradox», The Yale Law Journal, vol. 126, 3, pp. 710-805.

Larroulet, Cristián y Mochón, Francisco (1996): Economía (Madrid, McGraw-Hill).

López, Jorge (1999): «Las condiciones generales de la contratación y cláusulas abusivas», en Díez-Picazo, Luis: Las Condiciones Generales de la Contratación y Cláusulas Abusivas (Madrid, Civitas).

Mardones, Marcelo (2020): Lecciones de derecho económico. Regulación económica de los mercados. Vol. I (Valencia, Tirant lo Blanch). 
Morales, María Elisa (2017): «Extensión del derecho de consumo a contratos b2b. Corte de Apelaciones de Antofagasta, 21 de diciembre de 2016, rol 174-16, Castro Perlaza, Diana con Supermercado Tottus Calama», Revista Chilena de Derecho Privado, No. 29: pp. 329-335.

Narváez, Javier (2014): «Eficacia del control de las cláusulas abusivas en Chile. Control de los mandatos irrevocables", Revista Estudios Jurídicos Democracia y Justicia, No. 3: pp. 21-35.

Sandoval, Ricardo (2004): Derecho del Consumidor (Santiago, Editorial Jurídica de Chile).

Tapia, Mauricio (2004): «Regulación de las relaciones comerciales entre proveedores y distribuidores». Disponible en Microjuris, bajo la cita: MJD306 [Fecha de consulta: 24.05.2020].

Valdés, Domingo (2006): Libre competencia y monopolio (Santiago, Editorial Jurídica de Chile).

Vial, Bernardita y Zurita, Felipe (2011): Microeconomía (Santiago, Ediciones Universidad Católica de Chile).

Yrarrázaval, Arturo (1999): "Protección al consumidor y libre competencia», en Corral, Hernán (editor), Derecho del consumo y protección al consumidor. Estudios sobre la ley $N^{\circ} 19.496$ y las principales tendencias extranjeras (Santiago: Cuadernos de extensión jurídica, Facultad de Derecho, Universidad de los Andes).

\section{Otras fuentes consultadas}

Biblioteca del Congreso Nacional, Historia de la Ley 19.911.

Biblioteca del Congreso Nacional, Historia de la Ley 19.610.

Biblioteca del Congreso Nacional, Mensajes de S.E. Don Carlos Ibáñez del Campo, al Congreso Nacional al inaugurar el período ordinario de sesiones. 21 de mayo de 1957.

Biblioteca del Congreso Nacional, Proyecto de Ley de 1957.

Normas citadas

Ley $\mathrm{N}^{\circ} 20.169(16 / 2 / 2007)$ Regula la competencia desleal.

Ley $\mathrm{N}^{\circ} 19.496$ (7/3/1997) Ley que establece normas sobre la protección de los derechos de los consumidores.

Decreto Ley $N^{\circ} 211(22 / 12 / 1973)$ Fija normas para la defensa de la libre competencia.

\section{Jurisprudencia citada}

Requerimiento de la FNE contra CCNI S.A. y otras (2019): Tribunal de Defensa de la Libre Competencia, 24 de abril de 2019, Rol C-292-15. Disponible en: https:/www.tdlc.cl/nuevo_tdlc/wp-content/ uploads/sentencias/Sentencia_171_2019.pdf

Requerimiento de la FNE contra CMPC Tissue S.A. y Otra (2017): Tribunal de Defensa de la Libre Competencia, 28 de diciembre de 2017, Rol C-299-15. Disponible en: https://www.tdlc.cl/ nuevo_tdlc/wp-content/uploads/sentencias/Sentencia_160_2017_.pdf

Denuncia de particular por caso de competencia desleal (2017): Fiscalía Nacional Económica, 27 de junio de 2017, Rol No 2432-17 FNE. Disponible en: https://www.fne.gob.cl/biblioteca/actuaciones-dela-fne/investigaciones-de-la-fne/

Demanda de Netline Mobile S.A. contra Entel PCS Telecomunicaciones S.A. y otros (2017): Tribunal de Defensa de la Libre Competencia, 21 de marzo de 2017, Rol C-271-13. Disponible en: https:// www.tdlc.cl/nuevo_tdlc/wp-content/uploads/2017/03/Sentencia_156_2017.pdf 
Corporación Nacional de Consumidores y Usuarios de Chile con Movistar S.A., Claro Chile S.A. y Entel PCS S.A. (2016): Corte Suprema, 20 de abril de 2016, Rol No 11363-2015. ID Vlex: 633852033.

Demanda de Ramírez y Compañía Limitada contra Ministerio de Transportes y Telecomunicaciones (2014): Tribunal de Defensa de la Libre Competencia, 30 de julio de 2014, Rol C-256-13. Disponible en: https:/www.tdlc.cl/nuevo_tdlc/wp-content/uploads/sentencias/Sentencia_138_2014.pdf

Beatriz Lea Zuberman Comercializadora E.I.R.L. con One Smart Star Number Chile S.A. (2014): Corte Suprema, 7 de enero de 2014, Rol 6264-2013. ID Vlex: 484968046.

Demanda de Sonda S.A. contra Servicio de Registro Civil e Identificación (2013): Tribunal de Defensa de la Libre Competencia, 25 de octubre de 2013, Rol C-242-12. Disponible en: https://consultas.tdlc. $\mathrm{cl} /$ download/46533?inlineifpossible=true

Demanda de NETLANDCHILE S.A. contra el Ministerio de Transportes y Telecomunicaciones (2010): Tribunal de Defensa de la Libre Competencia, 22 de octubre de 2010, Rol C-179-08. Disponible en: https://www.tdlc.cl/nuevo_tdlc/wp-content/uploads/sentencias/Sentencia_105_2010.pdf

Requerimiento de la FNE contra Asociación Gremial de Dueños de Mini Buses Agmital (2010): Tribunal de Defensa de la Libre Competencia, 11 de agosto de 2010, Rol C-191-09. Disponible en: https:// www.tdlc.cl/nuevo_tdlc/wp-content/uploads/sentencias/Sentencia_102_2010.pdf

Requerimiento de la Fiscalía Nacional Económica en contra de Transportes Central Ltda. y otros. (2010): Tribunal de Defensa de la Libre Competencia, 7 de enero de 2010, Rol C-149-07. Disponible en: https://www.tdlc.cl/nuevo_tdlc/wp-content/uploads/sentencias/Sentencia_94_\%202010.pdf

Requerimiento de inaplicabilidad presentado por Universal Agencia de Turismo Limitada, respecto del artículo 43 de Ley 19.496, sobre protección de los derechos de los consumidores (2008): Tribunal Constitucional, 13 de mayo de 2008, Rol N 980-07-INA. Disponible en https://www.tribunalconstitucional.cl/ ver2.php?id=935

Consulta de GLR Chile Limitada sobre la compra de la totalidad de acciones de Iberoamerican Radio Chile S.A. (2007): Tribunal de Defensa de la Libre Competencia, 27 de julio de 2007, Rol NC173-06. Disponible en: https:/www.tdlc.cl/nuevo_tdlc/wp-content/uploads/resoluciones/ Resolucion_20_2007.pdf. 